\title{
A Review of Antennas for Picosatellite Applications
}

\author{
Abdul Halim Lokman, ${ }^{1}$ Ping Jack Soh, ${ }^{1}$ Saidatul Norlyana Azemi, ${ }^{1}$ Herwansyah Lago, ${ }^{1}$ \\ Symon K. Podilchak, ${ }^{2}$ Suramate Chalermwisutkul, ${ }^{3}$ Mohd Faizal Jamlos, ${ }^{1}$ \\ Azremi Abdullah Al-Hadi, ${ }^{1}$ Prayoot Akkaraekthalin, ${ }^{3,4}$ and Steven Gao ${ }^{5}$ \\ ${ }^{1}$ Advanced Communication Engineering (ACE) CoE, School of Computer and Communication Engineering, Universiti Malaysia Perlis, \\ Pauh Putra Campus, 02600 Arau, Perlis, Malaysia \\ ${ }^{2}$ Institute of Sensors, Signals and Systems, School of Engineering and Physical Sciences, Heriot-Watt University, \\ Edinburgh EH14 4AS, UK \\ ${ }^{3}$ Department of Electrical and Software Systems Engineering, The Sirindhorn International Thai-German Graduate School of \\ Engineering, King Mongkut's University of Technology North Bangkok, 1518 Pracharat 1 Rd., Wongsawang, Bangsue, \\ Bangkok 10800, Thailand \\ ${ }^{4}$ Department of Electrical and Computer Engineering, Faculty of Engineering, King Mongkut's University of Technology North Bangkok, \\ 1518 Pracharat 1 Rd., Wongsawang, Bangsue, Bangkok 10800, Thailand \\ ${ }^{5}$ School of Engineering and Digital Arts, The University of Kent, Jennison Building, Canterbury, Kent CT2 7NT, UK \\ Correspondence should be addressed to Ping Jack Soh; pjsoh@ieee.org
}

Received 21 November 2016; Revised 17 January 2017; Accepted 7 February 2017; Published 30 April 2017

Academic Editor: N. Nasimuddin

Copyright (C) 2017 Abdul Halim Lokman et al. This is an open access article distributed under the Creative Commons Attribution License, which permits unrestricted use, distribution, and reproduction in any medium, provided the original work is properly cited.

Cube Satellite (CubeSat) technology is an attractive emerging alternative to conventional satellites in radio astronomy, earth observation, weather forecasting, space research, and communications. Its size, however, poses a more challenging restriction on the circuitry and components as they are expected to be closely spaced and very power efficient. One of the main components that will require careful design for CubeSats is their antennas, as they are needed to be lightweight, small in size, and compact or deployable for larger antennas. This paper presents a review of antennas suitable for picosatellite applications. An overview of the applications of picosatellites will first be explained, prior to a discussion on their antenna requirements. Material and antenna topologies which have been used will be subsequently discussed prior to the presentation of several deployable configurations. Finally, a perspective and future research work on CubeSat antennas will be discussed in the conclusion.

\section{Introduction}

In general, satellites are structures that are capable of transmitting and receiving or relaying signals from space. Due to their location, they are able to provide a wide coverage area with long communication range. The development of the conventional satellites incurs significant amount of financial, time, and resources costs. However, a viable alternative to this is the deployment of picosatellites such as CubeSats. They cost less, consume less power, and allow fast development time but, at the same time, are feasible and robust, similar to conventional satellites.

CubeSats are satellite structures with a volume of $10 \mathrm{~cm}^{3}$ and a mass of less than $1 \mathrm{~kg}$, typically made of lightweight commercial-off-the-shelf components [1]. Due to their size and weight, CubeSats are known to be part of the picosatellite family. One of the first CubeSats was developed by the California Polytechnic State University (Cal Poly) in collaboration with Stanford University starting 1999 [1] and was launched in 2002 [2]. The Cal Poly's mission was aimed at using Stanford University's spacecraft named OPAL as the proposed CubeSat launcher [1]. This project began with the development of the standard launcher known as the Poly Picosatellite Orbital Deployer (P-POD). Besides the CubeSat structure, its theoretical criteria such as the weight and the size of CubeSat must comply with the launcher's specifications to ensure a successful deployment into space [1]. Several requirements for the P-POD deployer include 
aspects such as a space between CubeSat edges from the rail to avoid friction and ensure smooth deployment. Besides that, extended spaces need to be available for solar panels, antennas, or other components with possible extension of more than $10 \mathrm{~cm}$.

Since then, several types of CubeSats were developed with several sizes such as the $1 \mathrm{U}$ standard CubeSat with a unit of cube $\left(10 \times 10 \times 10 \mathrm{~cm}^{3}\right), 3 \mathrm{U}, 6 \mathrm{U}$, and $12 \mathrm{U}$ consisting of three, six, and twelve cube units. The choice of size is dependent on the installed components and launcher's specification. They are typically placed into the low earth orbit (LEO) ranging from $160 \mathrm{~km}$ to $2000 \mathrm{~km}$ in altitude [3], with a typical lifetime of several years working in space [4]. This paper provides a comprehensive review of the applications of picosatellites and the types of antennas available in literature. Most importantly, the challenges involved in their development and the innovative methods applied to these antennas in solving the space and power limitations in such compact satellites are also discussed. The existing works on picosatellite antennas are reviewed and summarized in a systematic way, with emphasis on their important deployable parameters such as stowage location, stowed size, and stow-to-deployment ratio besides conventional antenna parameters.

\section{Applications of Picosatellites}

Satellite technology is widely used in many aspects of today's life such as television broadcasting, mobile satellite, radar and imaging applications, and weather forecasting [5]. However, the recent introduction of picosatellites has enabled their application in a small segment of the field which has been conventionally supported by larger satellites for earth observation and space weather forecasting. Due to their size and development time, costs are significantly reduced compared to conventional satellites. The applications for CubeSats have been reviewed in several previous publications $[4,6,7]$. A general CubeSat overview and its capability have been described in [6]. Meanwhile, a general survey on the communication system of the CubeSat applications over the past several years have been discussed in [4, 7]. Besides the current applications explained in the following sections, CubeSats are currently still being improved and adapted for use in other more specific and advanced applications.

2.1. Earth and Climate Observation. Earth observation has been performed since 1960 by the United States (US) meteorological satellite [8]. A review of the requirements and capabilities of CubeSats for the earth science and observation has been performed in [8]. The purpose of earth observation is to measure earth characteristics to better understand the weather, natural disasters, pollutions, and water [9]. A satellite placed in the orbit will scan the image of the earth surface and map the focused area based on the radar concept [10]. It is also possible to measure the characteristics of soil using this technique [10] using a high gain antenna and radar.

Meanwhile, the European Space Agency (ESA) and the National Aeronautic and Space Administration (NASA) have both produced their first observing satellite in 1990 and
2000 [9]. A larger satellite for this application, ENVISAT, was built by ESA [9]. It is capable of fast and efficient observation [9]. The need for picosatellites such as CubeSats was quickly realized due to the need of mass-release payloads to ensure mass efficiency using a single launch [9]. Other researches involving nano- and picosatellites have been implemented and summarized in $[11,12]$. The best CubeSat researches so far include carbon dioxide measurements and GNSS radio occultation [13], a research on hyperspectral microwave atmospheric sounding by MIT's MICROMAS CubeSat [14], and gathering results of particle involving clouds and aerosol by NASA's Cloud CubeSat [15]. Besides that, CubeSats have also shown potential for education purposes. For instance, detailed earth observations have been performed using a CubeSat in [12].

For climate observation, satellite performance is crucial to ensure complete and accurate measurement results. For instance, one of the main limitations of the Tropical Rainfall Measurement Mission (TRMM) is the deployment of a number of instruments in LEO which were unable to provide complete measurement results by short-term climate observation [16-19]. However, this can be reduced by implementing the constellation of precipitation profiling instruments in LEO, at the cost of production timeline and resources [20]. Thus, CubeSat was chosen as an alternative structure for this application by optimizing its existing characteristics for a radar satellite [20].

2.2. Space Weather Forecasting. Another interesting application for CubeSats is known as space weather forecasting. Its purpose is to provide an initial warning of storms in the solar system by using several CubeSats in a cluster. The concept is to forecast the weather of the solar system by establishing a CubeSat with a specific payload and high antenna performance to transmit the data with a high rate to the earth. The rest of the CubeSats will use low performance antennas for communication between each satellite within the earth's orbit [21]. In such situations, the communication links between CubeSats are crucial as they are deployed with unspecific distances from the target orbit. Besides that, CubeSats have also been used for defence forces such as the Air Force for space monitoring. The interconnection of several CubeSats placed in LEO was able to optimize resources in such monitoring [22].

2.3. Space Research. CubeSats have also been utilized in a nanosatellite program known as the Nanosatellite Tracking of Ships (NTS) [23]. This trial program is intended to test the satellite in a real space environment to ensure communication between the receiving part of the Automatic Identification System (AIS) receiver radio and AIS transmitter in LEO within a range of $100 \mathrm{~km}$ [23]. This system is capable of collecting the message from space to provide the awareness of global marine traffic and for other common applications [23]. The NTS mission is to collect the AIS signal in the LEO range, to measure the surrounding radio frequency from $160 \mathrm{MHz}$ to $162 \mathrm{MHz}$ with noise level identification, and to provide a platform for future mission qualification [23]. The structure 
TABLE 1: Summary of the operating frequencies, data rate, and antenna gains for picosatellite applications.

\begin{tabular}{|c|c|c|c|c|}
\hline \multirow[b]{2}{*}{ Types of application } & \multicolumn{2}{|c|}{ Operating frequency band } & \multicolumn{2}{|c|}{ Communication performances } \\
\hline & $\begin{array}{l}\text { Application-specific frequency } \\
\text { (range) }\end{array}$ & $\begin{array}{l}\text { Communication with ground } \\
\text { station (range) }\end{array}$ & $\begin{array}{l}\text { Required transmitting } \\
\text { gain }\end{array}$ & Required data rate \\
\hline $\begin{array}{l}\text { Earth and climate } \\
\text { observation [9] }\end{array}$ & $\begin{array}{l}\text { L-band (1-2 GHz), Millimeter } \\
\text { wave }\end{array}$ & $\begin{array}{c}\text { VHF band }(130-170 \mathrm{MHz}) \\
\text { UHF band }(400-450 \mathrm{MHz}) \\
\text { S-band }(2-4 \mathrm{GHz})\end{array}$ & Minimum $17 \mathrm{~dB}$ & More than $9600 \mathrm{bps}$ \\
\hline $\begin{array}{l}\text { Space weather } \\
\text { forecasting [21] }\end{array}$ & X-band $(8-12 \mathrm{GHz})$ & S-band $(2-4 \mathrm{GHz})$ & $26 \mathrm{~dB} \& 37 \mathrm{~dB}$ & Up to $400 \mathrm{kbps}$ \\
\hline Space research [24] & $\mathrm{X}$-band $(8-12 \mathrm{GHz})$ & $\begin{array}{l}\text { VHF band }(130-170 \mathrm{MHz}) \text {, } \\
\text { UHF band }(400-450 \mathrm{MHz})\end{array}$ & $17 \mathrm{~dB} \& 37 \mathrm{~dB}$ & More than $32 \mathrm{kbps}$ \\
\hline Communications [25] & K-band (18-27 GHz) & K-band (18-27 GHz) & $45 \mathrm{~dB}$ & More than $6 \mathrm{Mbps}$ \\
\hline
\end{tabular}

of NTS is only $20 \mathrm{~cm}^{3}$ along with two strings for solar cells, which serve as the source power of the spacecraft attitude [23].

In space research study, CubeSat can also be utilized for asteroid exploration. The significant budget for such exploration can be reduced by utilizing CubeSats [24]. Such missions can be implemented using two methods: (1) using a single CubeSat as the explorer or (2) using a conventional satellite as a carrier of the CubeSat. For such applications, the operation in X-band is preferred for deep space exploration compared to the Very High Frequency (VHF)/Ultrahigh Frequency (UHF) band and the S-band [24].

2.4. Communications. Arguably the most important application of picosatellites is in the communication aspect. Identifying its requirements starts with estimating a good link budget to ensure efficient communication between the spaceto-earth or space-to-space communication links [25]. For communications between CubeSats, a higher operating frequency is preferred in the S-band, or specifically at $2.45 \mathrm{GHz}$. This is to enable signal reception by small antenna receivers using this band via the use of smaller antennas compliant to the CubeSat structure [25].

More recently, researchers have been exploring the possibility of optical communication systems in space between satellite and earth station known as quantum communications [26]. The satellite communicates by transmitting a laser in the optical field frequency range to a base station on earth with a line of sight (LOS) enabling the link establishment [26]. This concept of bidirectional communication is, however, susceptible to changes to the CubeSat position in orbit. Therefore, an additional payload with a tracking and acquisition system must be installed for CubeSat position detection. Several specifications have been proposed, including an uplink optical laser specified at $980 \mathrm{~nm}$, while its downlink was specified by $1550 \mathrm{~nm}$ [26].

In contrast with other applications, intersatellite communication is a process of cooperation between each of the CubeSats aimed at gathering and distributing specified data to one another before data transmission to earth [25]. Multiple CubeSats mainly collaborate for deep space research and space weather forecasting. A group of CubeSats in distributed locations will individually gather required data, similar to the Orbiting Low Frequency Antennas for
Radio Astronomy (OLFAR) project, the QB50 project, and applications described in the previous sections [21, 27, 28]. Such systems work like a wireless sensor network (WSN) with multiple nodes spread in space [25]. Based on projects mentioned in $[28,29]$, each of the satellites will connect to each other and share all information such as timing, positioning, and other related information, including the observation data. Another example of such communication system is the IRIDIUM satellite constellation, which uses frequencies ranging from $22.55 \mathrm{GHz}$ to $23.55 \mathrm{GHz}$ to enable stable route traffic via intraplane and interplane neighboring satellites [30-32].

2.5. Summary. A brief discussion of each CubeSat application is explained in this section. The application of antenna for CubeSat mainly serves two main links, either satellite-toearth or satellite-to-satellite links, ideally with high data rate. The applications which utilize CubeSats include earth and climate observation, research in space, space weather forecasting, and communication. Due to the different types of collected data and the variation of the required link capacities, frequencies of these applications will differ and so will type of antenna utilized and the required gains. The limiting factors in the link budget include the transmitting power, operating frequencies, and the inherent gain and radiation capabilities of different antenna topologies. These are crucial considerations to suit different applications, and their requirements for each are summarized in Table 1.

\section{Requirements for Picosatellite Antennas}

The effectiveness of the CubeSat communication system is determined by the link budget estimates, and one of the important components determining this is the performance of the antenna. The size of the antenna on the CubeSat structure is dependent on the required gain and operating frequency. Due to the need for multielement antenna arrays to boost gain, the use of miniaturization techniques is crucial in ensuring a suitable antenna size for implementation on picosatellite structure. Furthermore, the chosen antenna needs to exhibit suitable polarization to ensure the achievement of the desired performance even when designed in a compact size. In view of these challenges, 
antennas chosen to fulfill the requirements of picosatellites are expected to be rather distinct compared to those implemented on conventional satellites. Their requirements and parameters are stated in the sections below, while an overview of the different picosatellite antennas is summarized in Table 2.

3.1. Operating Frequency. There has been yet a series of standardized operating frequency for CubeSat's communication system. The early development of the CubeSat involved the use of amateur radio frequencies in the VHF and UHF bands due to its low cost and high accessibility by the end users involved in the development of the first CubeSat [1]. $\mathrm{UHF}$ and VHF band were also chosen as the frequency specifically for telemetry, tracking, and command (TT\&C) in CubeSats [33]. After several years since the first launch of the CubeSat, various antennas have been developed at different operational frequencies depending on their requirements and applications.

The wide use of the UHF and VHF bands for data and voice communications was also demonstrated by the TURKSAT CubeSat project. The antenna system development is divided into two parts. The first system is a receiver part consisting of quarter wavelength dipole antennas with a width of $3 \mathrm{~mm}$ and a length of $50 \mathrm{~cm}$ operating at $145 \mathrm{MHz}$. Meanwhile, the second section is a trifunctional transmitter antenna, for the downlink of the beacon, modems, and transponders. This antenna operates at $435 \mathrm{MHz}$ and consists of six-quarter wavelength dipoles similar to the receiver antenna. Hence, the total ten antennas used for the UHF and VHF bands in this project increased the system's cost and complexity [34].

Meanwhile, an S-band antenna for CubeSat was developed by team from MIT using the inflatable antenna concept. This antenna operating at $2.45 \mathrm{GHz}$ with a $10 \mathrm{~dB}$ gain is developed for the purpose of extending the exploration into Geostationary Earth Orbit (GEO) from LEO [35]. A reflector was added in the antenna structure for improved gain performance [36], which consequently resulted in the achievement of a high communication data rate [35]. This then extended the distance of the system from LEO to GEO in [36].

Besides UHF, VHF, and S-band, a CubeSat with Kaband operating frequency for radar applications has been introduced for deep space research by NASA. The antenna was designed in an umbrella-like reflector form and the feed horn placed at the center of the antenna as shown in Figure 1. The operating frequency is at $34 \mathrm{GHz}$ with a gain of $42.8 \mathrm{dBi}$ [37].

3.2. Circular Polarization. Besides the need to exhibit high gains at the target operating frequency, the polarization of a CubeSat antenna is also of importance. Circular polarized (CP) antennas are typically used in various applications of satellite communication due to its ability to receive randomly polarized signals better than a linearly polarized antenna. This is advantageous for long distance communication between a satellite and a ground station.

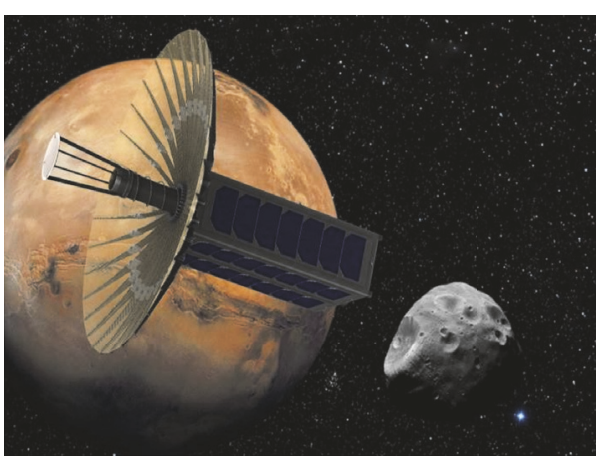

FIgURE 1: A CubeSat with Ka-band reflector antenna for deep space mission [37].

However, the design of such high gain, broadband, and directive circularly polarized antenna is challenging. One of the antenna prototypes which meets such requirements is proposed in [38], with a wide impedance bandwidth of $50.2 \%$ and $27 \%$ of axial ratio bandwidth. Meanwhile, the designs proposed in $[39,40]$ produced a wide $3-\mathrm{dB}$ axial ratio beamwidth higher than $120^{\circ}$. Besides that, a high gain circularly polarized antenna investigated in [41] exhibited a gain of more than $10 \mathrm{dBic}$.

A more sophisticated circularly polarized antenna design was enabled via the sequential phase feeding technique [39]. More than $10 \%$ of impedance bandwidth was produced with a high axial ratio bandwidth with a reasonably miniature $\left(0.533 \lambda_{0} \times 0.533 \lambda_{0}\right)$ form on a Rogers RO4003D substrate; see Figure 2 [39]. This substrate features a relative permittivity of 3.55 and a thickness of $0.813 \mathrm{~mm}$, enabling the antenna operation at $1.6 \mathrm{GHz}$ [39]. The design consists of two pairs of complementary dipole antennas located parallel to each other on a square shaped substrate. As shown in Figure 2(a), each dipole is connected to a phase shifter centered on the substrate. Each arm is designed with a $90^{\circ}$ phase difference to feed the circularly polarized antenna. The four striplines were combined with a patch to form a balun, enabling the dipole to operate in a balanced mode, as shown in Figure 2(b). The final structure exhibited a $10 \mathrm{~dB}$ bandwidth of about $31 \%$ and a $3-\mathrm{dB}$ axial ratio bandwidth of $1.6 \%$, with a peak gain around 5 dBic [39].

Another technique to provide high gain and wide bandwidth for circularly polarized antennas is by sequentially rotating the feed to enable circular polarization and increase gains [42-45]. This technique can be generally implemented using a number of identical radiating elements, which are fed sequentially using a $90^{\circ}$ phase difference to enable boresight circular polarization. For instance, the design in [42] consists of four sequentially rotated circular slot antennas (in a $2 \times 2$ configuration) and a sequentially rotated feed network. The circular feed network is chosen to minimize discontinuity between the feed, with each arm placed perpendicular to each other to generate circular polarization by adapting the $90^{\circ}$ rotating technique. The final design indicated significant improvements; the single antenna gain of $3.6 \mathrm{dBic}$ is improved to be $8.7 \mathrm{dBic}$ for the array with 


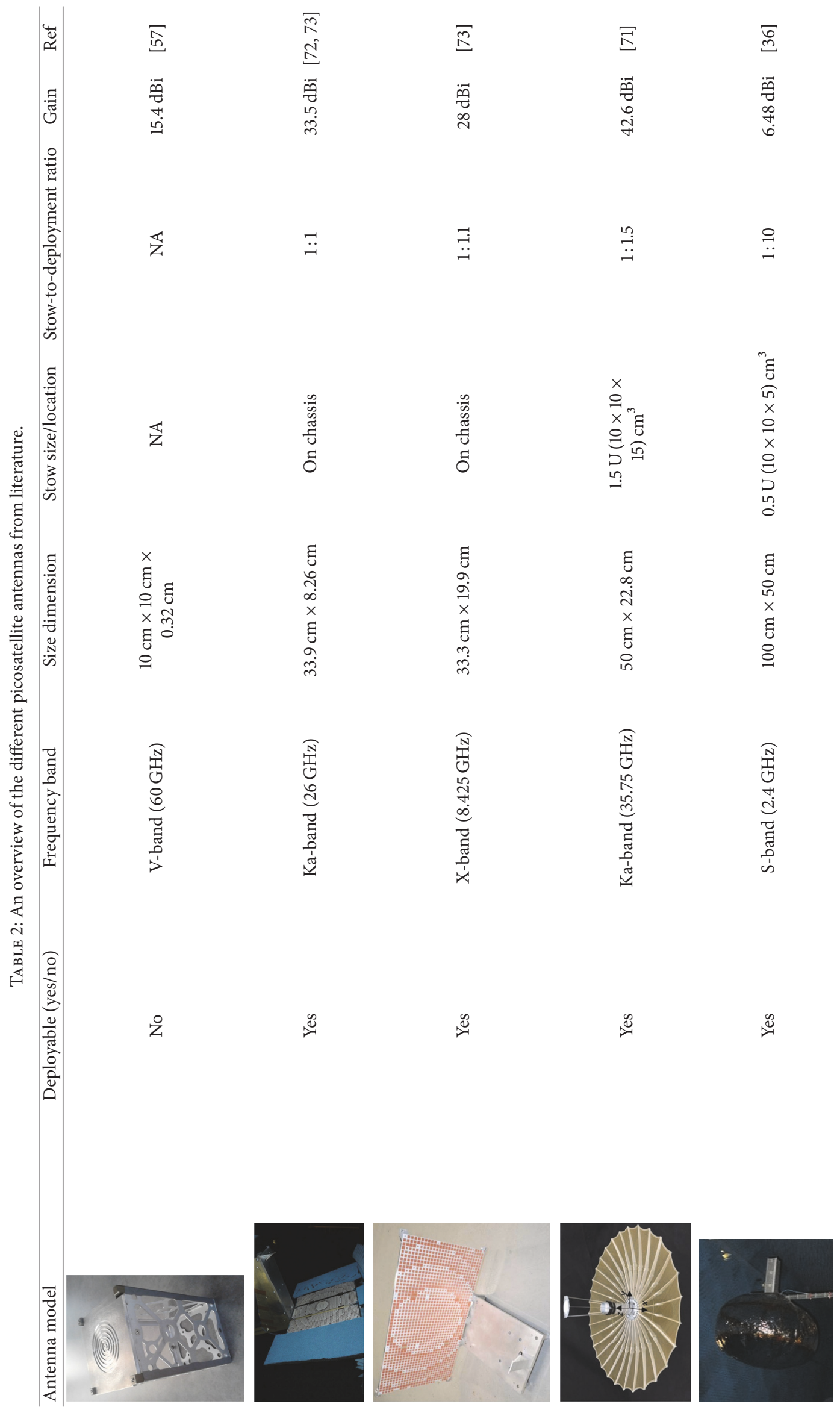




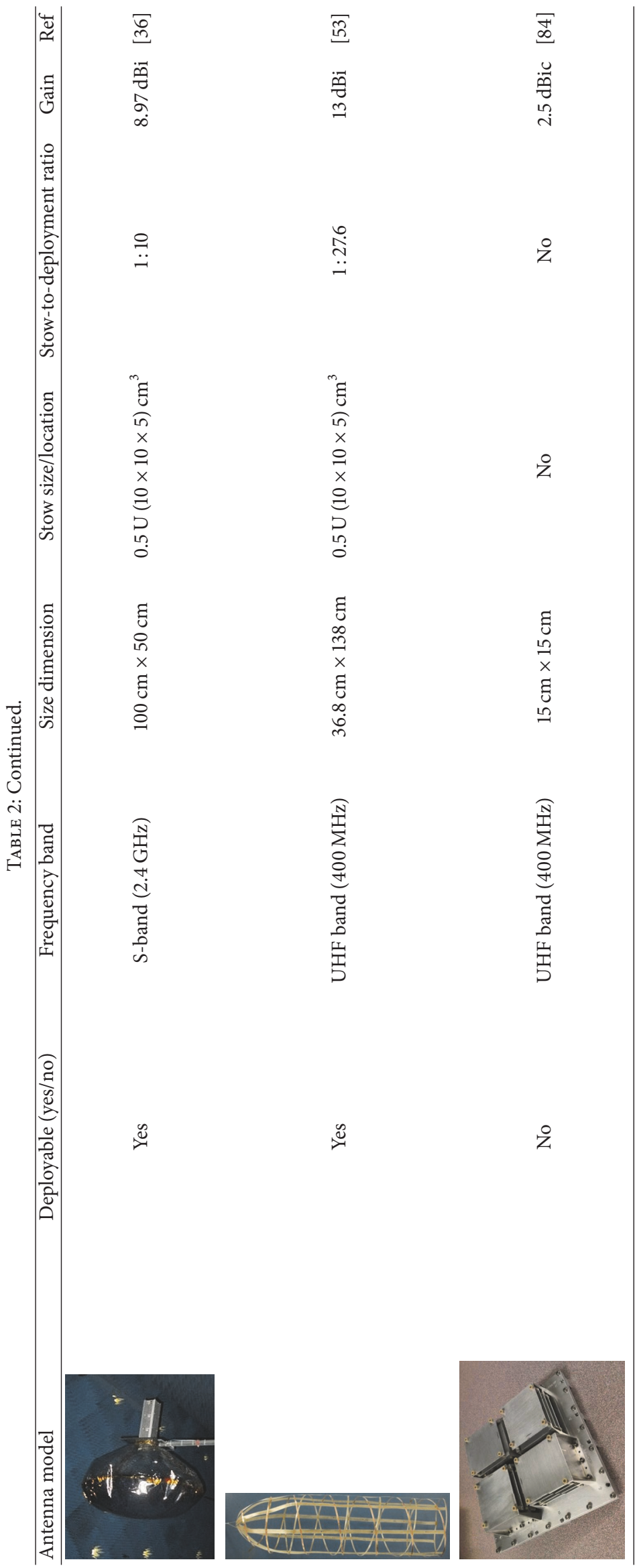




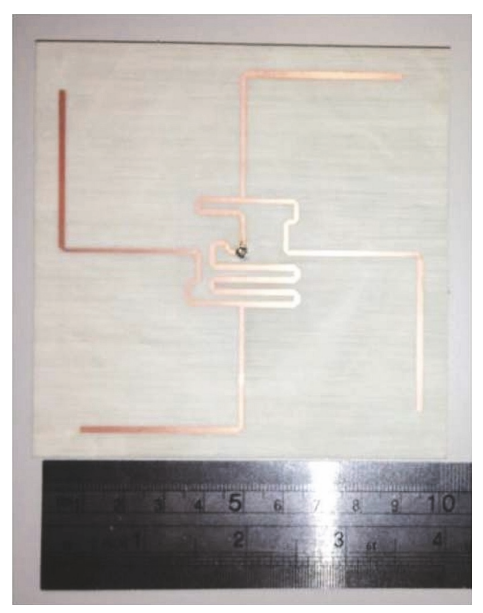

(a)

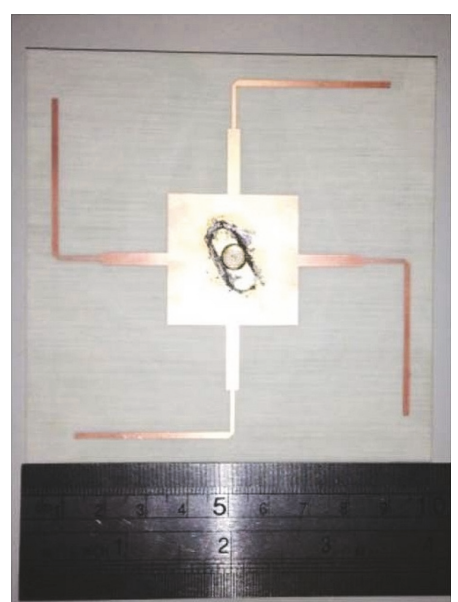

(b)

FIGURE 2: CP antenna with phase shifter. (a) Front view and (b) rear view [39].

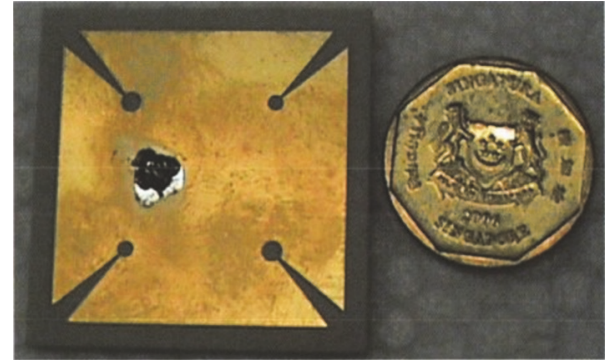

FIgURE 3: Compact antenna with symmetrical slit [46].

an impedance bandwidth of $3.8 \mathrm{GHz}$, operating from 4.2 to $8 \mathrm{GHz}$ [42]. In comparison, a wider impedance bandwidth of $6.2 \mathrm{GHz}$ (between 4.8 and $11 \mathrm{GHz}$ ) is exhibited by the single element antenna. However, its $3 \mathrm{~dB}$ axial ratio bandwidth is approximately $1 \mathrm{GHz}$ in contrast to $1.9 \mathrm{GHz}$ for the antenna array [42]. Similarly, the circular polarized antenna described in [45] consists of four identical rectangular patches and feed networks located on the top and bottom surface of a substrate respectively, with an overall size of $10 \times 10 \mathrm{~cm}^{2}$. Each patch is placed orthogonally on each side of a square ring. A $90^{\circ}$ phase difference between the two orthogonal pairs of patches produced by the feeding network enabled circular polarization at boresight [45]. This feeding network is typically designed using quarter-wave transformers adapting the Wilkinson power divider structure. Each patch is fed equally from the feeding network after the input power is divided using three power dividers. The antenna operates at $2.45 \mathrm{GHz}$ with a gain of $5.9 \mathrm{dBi}$ for a single patch element, which is improved to $7.3 \mathrm{dBi}$ for the complete structure, with a near-to-one axial ratio.

Circular polarized antenna could also be implemented on a single patch antenna by applying elements on its surface such as truncation, slot, or parasitic elements. An example is shown in Figure 3 where a microstrip antenna with several additional splits on each corner of the antenna to enable

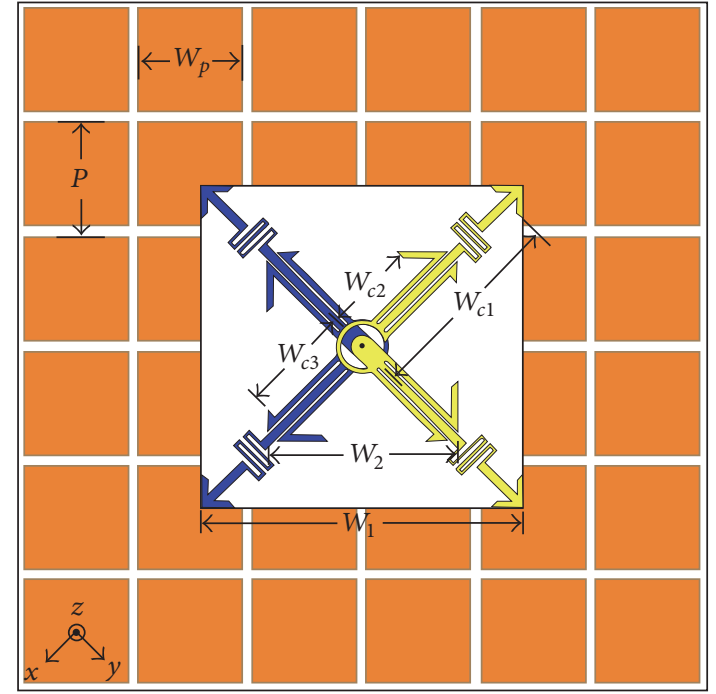

FIgURE 4: The illustration of the compact circular polarized crossed dipole antenna with high impedance surface (HIS) on the back of the antenna [48].

circular polarization with a compact size [46]. Comparison of the same antenna on two different substrates, FR- 4 and Rogers RO4003C, shows that the latter performs better compared to FR-4 substrate in terms of gain without any size changes. The FR-4 impedance bandwidth was 3.85\% with a 3 $\mathrm{dB}$ axial ratio bandwidth of $1.5 \%$ and a peak gain of $0.8 \mathrm{dBic}$. Meanwhile, the antenna on Rogers RO4003C resulted in an impedance bandwidth of $1.5 \%$ and an axial ratio bandwidth of $0.5 \%$ and a peak gain of $3.4 \mathrm{dBic}$ [46], indicating that the substrate significantly influences the resulting gain.

Another method to create circular polarization is by using crossed dipole antenna fed with an equal amplitude but $90^{\circ}$ of phase difference [47-50]. The dipole illustrated in Figure 4 is composed of delay lines with a $90^{\circ}$ phase difference. This structure is centered on the antenna design to form a ring 
shape. Both parts of the dipole antenna were crossed between a ring at the center and fed by a $50 \Omega$ coaxial cable $[47,48]$. The dipole on the top and bottom side of the substrate is connected with the inner and outer layer of coaxial cable, respectively $[47,48]$. With some modification on the dipole structure, a circular polarization was exhibited by this design with an axial ratio less than $3 \mathrm{~dB}[47,48]$.

3.3. Size Compactness/Deployability. Perhaps the most critical characteristic of a CubeSat antenna is its size compactness. There is yet to be a series of standardized antenna operating frequency for CubeSats and it will be almost impossible to design an antenna capable of catering to all frequencies. Thus, antenna miniaturization techniques are important, especially when designing antennas operating in the lower VHF and UHF bands due to its intrinsic wavelength. Antenna miniaturization techniques that result in electrically small antennas are extremely desirable especially in applications with limited space constraints. Several instances of such techniques include the folding, spiraling, and meandering of line antenna structures [40, 51, 52]. Besides size, high gain and circular polarized characteristics are also required for CubeSats. A method to overcome this limitation is to enable the stowage of the antenna prior to deployment in space. An example of this in the UHF band is a deployable helical antenna with a resulting gain of approximately $13 \mathrm{dBi}$ to operate at $400 \mathrm{MHz}$ [53]. It was designed with a dimension larger than the size of the CubeSat. The use of the flexible materials allowed the antenna to be stowed by consuming half the space available on the CubeSat before deployment [53]. Despite the fact that designing small antennas operating in the S- and K-band is less challenging compared to VHF and UHF antennas, the size of the antenna as compared to the wavelength mainly determines the gain. An example of this is presented in [54], where a $60 \mathrm{GHz} \mathrm{V}$-band antenna was developed to fit the CubeSat chassis resulting in a $15.4 \mathrm{dBi}$ of gain and used for intersatellite CubeSat communication link [54].

On the other hand, a compact sized patch antenna is capable of producing high gains by the integration of a large reflector, at the cost of its overall size. However, the large size of the reflector can be realized using flexible materials, which can then be stowed prior to its deployment in space to comply with the CubeSat size [35]. An instance of this is the $10 \mathrm{dBi}$ gain S-band antenna demonstrated in [35], which extended a LEO range of communication to the GEO range.

Apart of electrically small antennas, a compact smart antenna has also been proposed which features low cost and low power [55]. This antenna prototype operates between $2.3 \mathrm{GHz}$ and $2.55 \mathrm{GHz}$. Results indicated that the antenna is capable of beam scanning of over $360^{\circ}$ in the horizontal plane, achieving a gain of $4.0 \mathrm{dBi}$ and a front-to-back ratio of $20 \mathrm{~dB}$.

3.4. Summary. Numerous antenna designs have been suggested to comply with the requirements of standard CubeSat structures. One of the most important antenna requirements for satellite communication is their circular polarized property, which is capable of reducing losses in the long distance links between space and earth. However, such requirement adds to the design complexity. Thus, it is important that circularly polarized antennas are miniaturized and be made deployable to suit picosatellites. Antennas operating using lower frequencies benefit the propagation links due to their longer wavelengths and lower required gains, whereas operation in the higher frequencies eases the antenna design requirement in terms of size. A detailed summary of the available CubeSat antennas in literature is provided in Table 2, highlighting several important aspects to better develop antennas suitable for different operating frequencies.

\section{Materials for Picosatellite Antennas}

Material is one of the most important aspects in developing an antenna. Besides the need to comply with space operating environments, material selection also needs to be determined according to the operating frequency, gain requirements, and whether a deployable form is needed. If this is the case, possible flexible materials such as Kapton polyamide and Mylar films are suited. Besides that, conventional rigid substrate boards and lenses may also be chosen due to their suitability for use in space applications. The following sections discuss the use of these materials in detail.

4.1. Boards. Conventional substrates are popular due to their mechanical robustness for the space environment. Despite their small thickness, commercial and well-characterized boards such as those from Rogers could withstand the high heat illumination during propulsion from ground to space $[45,56]$. Besides thickness, these materials must also be lightweight to ensure efficient operation in space. The design on the CubeSat chassis in [45] had a size of $39.7 \mathrm{~mm}$ (length) $\times 12 \mathrm{~mm}$ (width) and thicknesses of $1.52 \mathrm{~mm}$ and $0.508 \mathrm{~mm}$. Its substrate relative permittivity of 2.33 resulted in a gain of $7.3 \mathrm{dBi}$.

4.2. Conventional Metals. A number of earlier antenna designs used conventional conductive and rigid materials. They provided heat dissipation, mechanical robustness, and possibly longer lifespan. A rigid antenna design was proposed using aluminum material for CubeSat in [57]; see Figure 5. This design named "Bull's Eye" is integrated on the chassis using 6-indented rings to result in operation in the $60 \mathrm{GHz}$ band. The number of indented rings shifts the frequency either upwards or downwards, and the number of seven rings was chosen due to its compliance with the intended CubeSat application [57]. In addition, the antenna and its specifications are summarized in Table 2.

4.3. Films. Mylar film has been used by NASA for the Echo Balloons project [58] and several other projects, among others $[36,59,60]$ due to its ease of availability. Besides that, one of the more popular materials used for small antennas is the Kapton Polyimide film. Its advantages include flexibility, good resistance over a number of chemical solvents, and compatibility to high temperatures ranging from $-269^{\circ} \mathrm{C}$ to $+400^{\circ} \mathrm{C}$, making it suited for space applications. Despite 


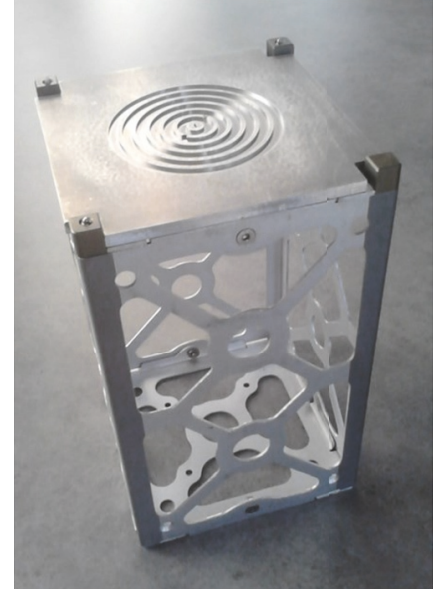

Figure 5: The Bull's Eye antenna on a CubeSat chassis [57].

not being used for satellite antennas, this material was used recently in the development of a dipole using an inkjet printing method [61]. Investigations indicated that the antenna prototype can be bent with a good flexibility without permanent deformations on its surface [61-64] and potentially integrated with a deployable mechanism as an antenna.

4.4. Membranes. Membranes have been used as reflectors recently in satellite communications. Featuring a total reflective surface with a diameter of $300 \mathrm{~cm}$, it is supported by a canopy built from 40 pieces of tension cables to enable 0.5 focus length to aperture ratio. More specifically, the membrane surface was built using $0.025 \mathrm{~mm}$ thick polyamide Kapton film type VN, supported by Nylon tension cables along with additional components such as cords, springs, and adjustment devices to ensure compliance to a pressure value of $15.07 \mathrm{~N}$ [65]. Results indicated that the reflector surface error is less than $1 \mathrm{~mm}$ root mean square ( $\mathrm{rms}$ ) when utilizing a Nylon-based boom.

4.5. Summary. Due to the more challenging space environment, antennas are required to be designed with suitable materials to ensure its proper operation after launch. Several potential materials have been discussed in this section, which can be categorized into two: rigid and flexible materials. Rigid materials such as high performance substrate boards and conventional metallic plates are suitable for space and are usually implemented on the CubeSat surfaces or deployed in folded forms. Besides that, the fabrication method of rigid, substrate-based antennas is also compatible with the current printed circuit board (PCB) technology, which enables manufacturing accuracy. Besides dielectric-based materials, the fabrication of more complex and fully metallic structures such as the Bull's Eye antenna can also be performed using specialized computer automated machinery. However, the use of such rigid materials limits the capability of these antennas' integration with the CubeSat structure, as they need to be either compact or folded in some way to ensure efficient space utilization.

Meanwhile, flexible materials such as films and membranes are more likely to be stored within the CubeSat during launch and deployed in space. An advantage with the use of deployable antennas is that it relaxes the robustness of requirement of their materials. Films such as Kapton are capable of withstanding up to $400^{\circ} \mathrm{C}$ and these antennas may be additionally protected in a case within the CubeSat structure. Due to the thinness of these flexible materials, optimizing the antenna may be more complex. This is due to the need to ensure reasonable antenna bandwidth using the combination of permittivity and the substrate thickness. Moreover, thin conductors may also potentially affect conductivity, which in turn also degrades antenna gain and radiation performance. Fabrication of these films to form antennas can be done in several ways, including inkjet printing or conductive paint spraying. Such technologies require specialized machines and well-characterized processes to ensure fabrication accuracy. While methods such as spray painting on films or membranes cost less in terms of technical complexity, greater efforts are required to realize small dimensions. In summary, it can be concluded that materials used in CubeSat must first consider reliability in space, space requirements on the picosatellite, and, finally, the antenna topology which is planned to be realized using these materials.

\section{Types of Picosatellite Antennas}

As summarized in the previous sections, it will be challenging to design an antenna which is compliant with all frequencies. Besides being dependent on the chosen materials, CubeSat antenna characteristics are mainly dependent on the frequency and its applications. Typical radiation pattern of each antenna type determines the footprint and the earth coverage area of the space-to-earth communication or the radar system. Unlike geostationary satellites, the footprints of LEO satellites are not fixed on a specific area on earth. However, the moving footprint determined by the orbit of the LEO satellite is directly linked to the time and region of visibility. A detailed investigation on the coverage area of small LEO satellites was reported in [66]. For the ground station, this means that a tracking mechanism is required to ensure the communication link with the satellite during the flyover period. Ideally, the CubeSat antenna should show the main lobe of its radiation pattern in the normal direction towards the earth surface (nadir). Thus, in case of directive antennas, a precise attitude control is required to control the footprint. This is challenging to be implemented on CubeSats due to the limited space for such attitude control elements such as momentum/reaction wheels or thrusters. There are ongoing research works regarding passive attitude control using permanent magnet [66] and hysteresis rods or magnetic torques [67] to overcome this limitation, especially for $1 \mathrm{U}$ CubeSats. The following section will describe the types of antennas available for CubeSats reported in the literature. 
5.1. Patch Antennas. Several CubeSat antennas are designed based on the patch topology due to its size and mass and planar compliance. The antenna was developed on the same Rogers substrate with two different thicknesses: $1.52 \mathrm{~mm}$ and $0.508 \mathrm{~mm}$. A rectangular shape was chosen to comply with the CubeSat chassis structure, resulting in a gain of $7.3 \mathrm{dBi}$ and directivity of $8.3 \mathrm{dBi}$ at $2.4 \mathrm{GHz}$ [45].

Meanwhile, issues related to deployments can be avoided by using such patch antennas for the antenna to radiate towards the upper half space with a circular polarization [56]. Such antennas are typically mounted on the surface of the CubeSat and mutual coupling can be avoided when using other patch antennas mounted on adjacent surfaces [56].

5.2. Monopoles/Dipoles. In the earlier stages of CubeSat development, monopoles and dipoles are typically the antenna of choice as part of the communication system $[1,68$, 69]. Their omnidirectionality provides wide signal coverage, especially when the CubeSat operates in the UHF band.

To cater for the limited space on CubeSats, most developers have tried to maintain the use of a single antenna to maintain simplicity and avoid the use of deployment mechanism $[1,34,68]$. However, several other researchers implemented simple monopole antennas which are deployable using a tape-spring method [70]. The antenna operates at $250 \mathrm{MHz}$ using a length of $55.88 \mathrm{~cm}$ and a ground plane sized at $114.3 \times 152.4 \mathrm{~cm}^{2}$ [70]. Repeatability assessments indicate that the antennas do not exhibit significant reflection coefficient changes after being deployed for 10 times. The antennas achieved almost $2 \mathrm{dBi}$ gain with an impedance bandwidth of about 8\% [70].

5.3. Reflector Antennas. Similar to parabolic antennas, reflector antennas are fed from the center of antenna to transmit and receive signals. For CubeSats, such antenna topology is mainly used in radar applications due to its high gain capability. One of such designs is developed for a $6 \mathrm{U}$ CubeSat in [71]. It is stowed within one and a half volume of the intended CubeSat and its ribs are built using very stiff material to support the antenna surface.

To simplify the deployment configuration, a viable alternative is to introduce axial symmetry to the reflector. The overall structure will then consist of a subreflector and horn antenna within the same deployment mechanism. To maintain the same level of storage space for the horn antenna, the subreflector must be set at a length of $22 \mathrm{~cm}$ to ensure it does not exceed the vertex. Meanwhile, a Cassegrainian design with $0.5 \mathrm{~m}$ of reflector and $0.25 \mathrm{~m}$ of focal length has been integrated with deployment mechanism in [71]. Several specifications of the antenna are summarized in Table 2.

Besides that, a novel design of inflatable antenna has been developed recently in [35]. The antenna consists of a patch and reflector antenna designed using different materials. This antenna specifically operates in the S-band and radiates signals for CubeSat communication at $2.4 \mathrm{GHz}$. Meanwhile, an inflatable membrane was developed using metalized Mylar film with a thickness of $50.8 \mu \mathrm{m}$ and works as the reflector for the signals radiated from the patch antenna.
A thinner 25.4 $\mu \mathrm{m}$ Mylar film was then used as the holder to combine the reflector antenna with the CubeSat chassis. This reflector antenna and its holder can be inflated using a small quantity of benzoic acid-based sublimating powder placed inside it before the deployment process. This powder will then turn into gas to allow for the inflating of the antenna with a pressure of $10^{-3}$ Torr, similar to other common injectors. The reflector can continue to be inflated using this powder even if leakage occurs on the membrane in space.

5.4. Reflectarray Antennas. Reflectarrays generally consist of an antenna and a reflectarray surface. The antenna is placed facing the reflector, which in turn points the signal towards the direction of CubeSat communication. The $3 \mathrm{U}(10 \times 10$ $\times 30 \mathrm{~cm}^{3}$ ) ISARA CubeSat was one of the CubeSats which uses reflectarrays integrated on its solar panels [72]. The downwards facing antenna reflector was placed behind the upwards facing solar panel of the CubeSat. It is capable of stowage via flipping and attachment around the CubeSat. A patch antenna which radiates signals was located opposite the antenna reflector to operate in the Ku-band at $26 \mathrm{GHz}$. A high resulting antenna gain of $33.5 \mathrm{~dB}$ was exhibited.

The similar concept was used in another CubeSat known as MarCO [73]. This $3 \mathrm{U}$ CubeSat consists of several payloads and two large solar panels mounted side by side on the bottom of the CubeSat [73]. In contrast to the previous work, the antenna reflector is mounted on the opposite end of the CubeSat away from the solar panels; see Figures 6(a) and 6(b). Besides this, the detailed specifications for both antennas (including for ISARA and MarCO) are summarized in Table 2.

5.5. Spiral/Helical Antennas. Several spiral or helical techniques for CubeSats have also been developed recently [53, 54]. One is known as the "Bull's Eye" antenna consisting of several circular rings of different diameters. The smallest ring with a diameter of $7.12 \mathrm{~mm}$ is located at the center of this structure and surrounded by another seven larger rings indented at a depth of $0.91 \mathrm{~mm}$ on a $3.2 \mathrm{~mm}$ thick aluminum plate to operate at $60 \mathrm{GHz}$ for $59 \mathrm{GHz}$ to $71 \mathrm{GHz}$ intersatellite communication [54]. As illustrated in Figure 7, the overall size of the antenna is $10 \mathrm{~cm}^{2}$, and additional incisions of $10 \mathrm{~mm}^{2}$ are introduced at each corner of the square shaped antenna to suit with the CubeSat chassis. Its gain exhibited at $60 \mathrm{GHz}$ is $19.1 \mathrm{dBi}$ with a $10-\mathrm{dB}$ impedance bandwidth of $8.4 \%$.

Besides rings, helical antennas operating in the UHF band has also been introduced for use on CubeSats [53]. Its operation at $400 \mathrm{MHz}$ resulted in a relatively large antenna compared to other high gain antennas for CubeSats. The design was integrated on a $1.5 \mathrm{U}$ CubeSat within a storage space of $0.5 \mathrm{U}$. It was designed using a five-turn coil built using a $0.0889 \mathrm{~mm}$ thick adhesive copper conductor extending outwards from the CubeSat at a $12^{\circ}$ pitch. It features a framework of fiberglass/thermoplastic tape strips with a column length of $138 \mathrm{~cm}$ and a diameter of $37 \mathrm{~cm}$. The structure utilizes two opposing helical elements' wound 


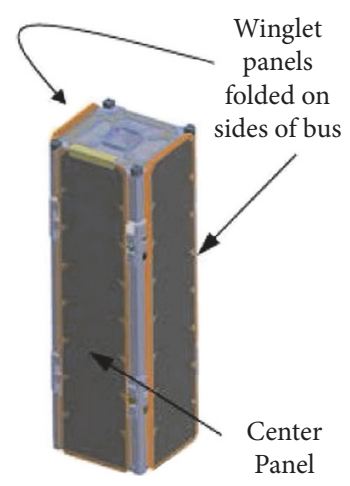

Panels stowed

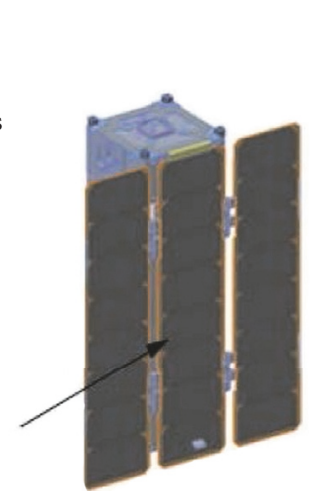

Panels flip out

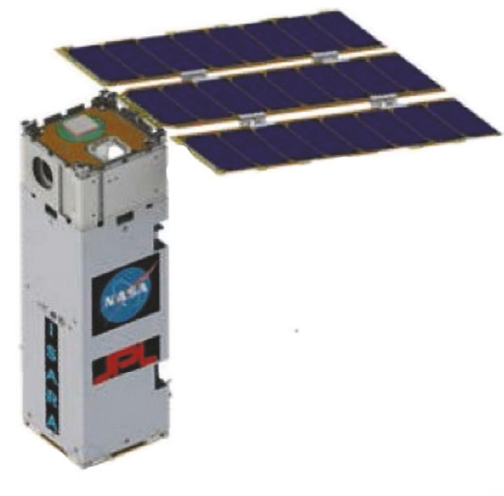

Panels fully deployed

(a)

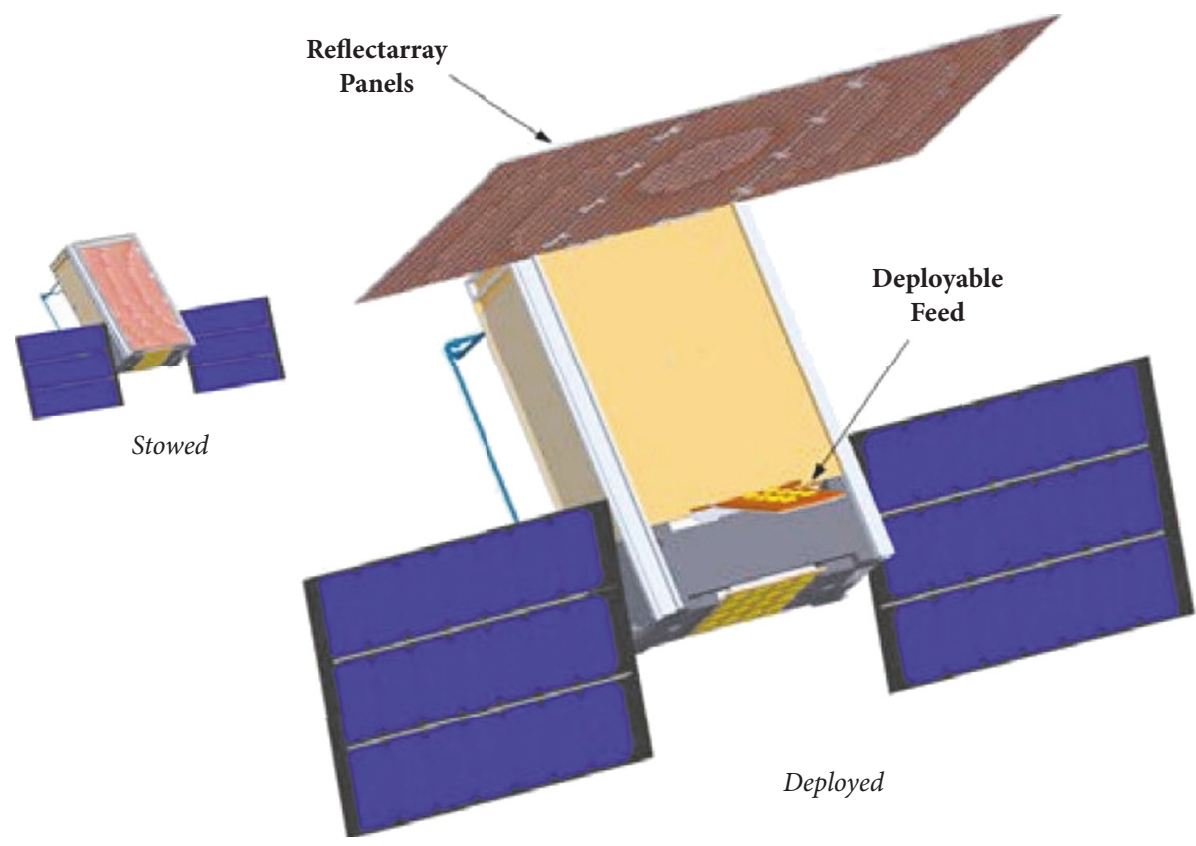

(b)

Figure 6: (a) ISARA CubeSat [72]. (b) MarCO CubeSat [73].

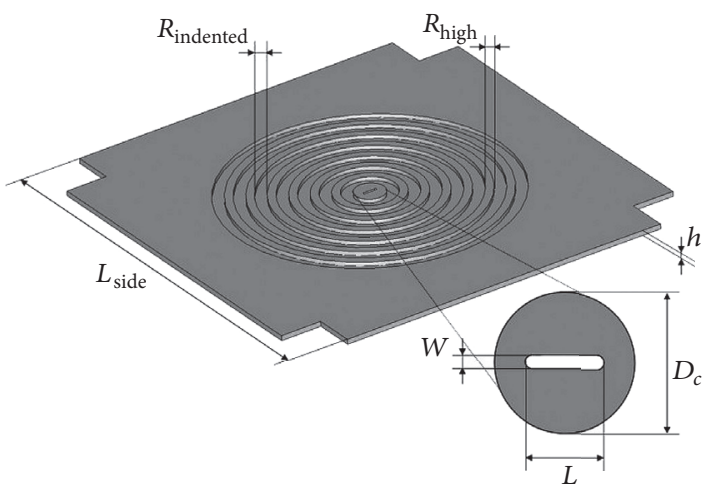

Figure 7: The "Bull's Eye" antenna [54]. 
clockwise and counterclockwise terminated at its top section. The ground plane with a diameter of $60.96 \mathrm{~cm}^{2}$ was made from a single layer of aluminized Kapton film and supported by four pieces of fiberglass rods with a diameter of $0.8128 \mathrm{~mm}$. During storage, the antenna was folded and rolled into a small structure and is deployed using the release of the stored strain energy. A gain of $13 \mathrm{dBi}$ and an axial ratio bandwidth of about 55\% are exhibited [53]. Both antennas and their related information are summarized in Table 2.

5.6. Summary. It can be observed that antennas for CubeSat applications have been intensively developed in recent years. Wire antennas such as dipoles and monopoles were initially used for the first CubeSat to communicate with the ground station. However, such antennas are known to be limited in terms of gain and result in large sizes when using conventional designs. Moreover, their omnidirectional radiation behavior may not be suitable for all picosatellite applications, especially when a directive radiation is required. On the contrary, antennas based on patches are preferred for picosatellite communication due to their planar form, simplicity, and costeffectiveness. Designing patch antennas requires the accurate characterization of the substrate and conductive materials, as their variation may result in frequency shifting of the already narrowband reflection characteristics. For higher frequencies, integration of patch antennas on the CubeSat (e.g., on one of its sides) is straightforward due to the compact resulting antenna dimensions. However, for low frequencies such as VHF or UHF, various miniaturization techniques are required to ensure that these patch-based antennas are able to be integrated with the CubeSat structure. Another option would be to design these patches into several sections which are foldable or can be combined in some way upon the placement of the satellite into orbit. Simple deployment methods such as spring-type can also be seen in wire loop antenna types such as spiral and helical antennas, which are used for long distance communication. More advanced high gain antennas such as reflector antennas and reflectarrays capable of deep space missions and improved satellite-toground station communications are also proposed at the expense of increased complexity. These antenna topologies almost certainly require mechanisms of deployment to cater for their sizes. The deployment mechanisms from literature may include mechanical components to ensure antenna robustness after deployment while ensuring flexibility during stowage. Considerations also need to be given to metallic supporting parts which are part of the deployment mechanism, as this could affect signal radiation or add on the stow-to-deployment ratio, as summarized in Table 2. In short, antennas with deployable capability are very much needed to comply with CubeSats' size and performance requirements. The design process must be balanced between antenna performance, cost, and space available on the proposed CubeSat structure, thus making the choice of flexible materials a critical factor. Besides these, the main challenge in CubeSat antenna design is ensuring the performance of the antenna and the deployment mechanism are unaffected by the CubeSat structure and vice versa.

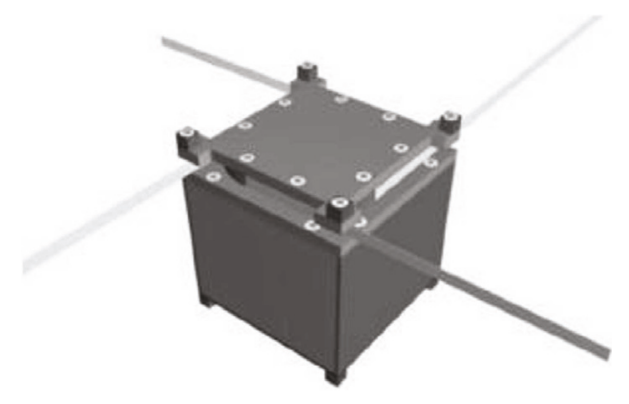

Figure 8: The deployable antenna used in PolySat [74].

\section{Deployment Mechanisms for Picosatellite Antennas}

The use of low frequencies, such as the UHF band, typically results in large antenna dimensions. Besides implementing miniaturization techniques, a more efficient option to maintain a high gain level is to integrate the large antenna with deployable mechanisms to comply with the limited CubeSat real estate.

Besides that, reflectors are also needed to improve gain in higher frequency antennas such as in the S-band, at a cost of size. Antenna deployment process typically occurs in a two-step process, namely, stowage and deployment. Latest developments in deployable mechanisms for CubeSats are discussed in more detail in the following sections.

6.1. Tape-Spring Model Deployment. The tape-spring deployment model is one of the earliest methods adapted in CubeSat applications, similar to the method used for OPAL [74]. As shown in Figure 8, it consists of two independent dipole elements located at the corners of the CubeSat chassis operating in the UHF band [74]. This deployable concept was produced based on a roller system which is capable of deploying the antenna within a few seconds [74]. A monofilament was used to hold the antenna using a small nichrome wire before a small amount of current was produced to heat the monofilament to release the antennas [74].

Meanwhile, an improved version of this method has been developed in [70]. A curved bistable composite tapespring was used to deploy the antenna in space using the roll concept. Compared to the normal tape-spring discussed in the previous section, this version utilized two stable tapesprings with an elastic structure. This provides simplification as less effort is required for deployment using a single rotary actuator compared to the use of neutrally elastic tape-springs.

6.2. Umbrella-Like Structure. A symmetrical, umbrella-like deployment mechanism is shown in Figure 9. During storage, the reflector, feed horn, and subreflector were kept inside the stowage space, with a size of no more than $0.5 \mathrm{U}$. Upon arrival at the orbit, the mesh reflector opens, releasing the desired components [71].

Location of such deployable antenna needs to be selected with care. From Figure 9, the deployable antenna needs to be mounted on the other end of the CubeSat chassis to avoid 


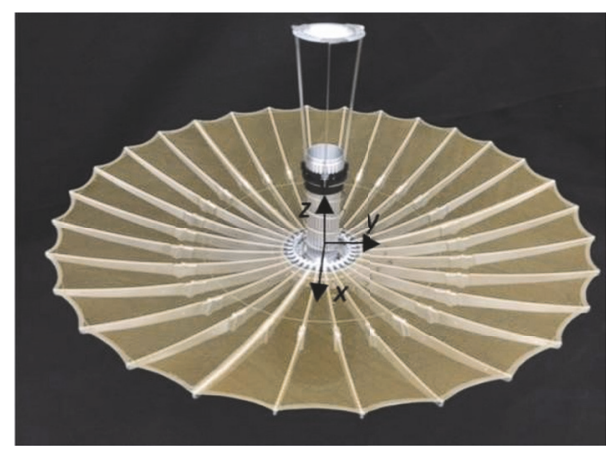

FIgURE 9: Mechanical deployment [71].

being in the way of the solar panels. Such mechanism is built using steel spring materials and is flexible enough to be bent or flipped. Prior to deployment, the antenna is bent $180^{\circ}$ and placed in parallel with the CubeSat chassis. The deployment process is initiated by heating a Nylon wire which is attached to the antenna and the CubeSat chassis and at the same time is connected with a nichrome wire. Finally, the antenna will be fully deployed in a vertical form [71].

6.3. Inflatable Mechanism. Inflatable antennas are advantageous in several aspects, which include efficient cost of manufacturing and small mass and requires less stowage space. In the 1950s deploying inflatable antennas is a sensitive process due to the unstable inflating gas and the difficulty in maintaining inflation in space [35]. However, a major breakthrough in this technology was demonstrated in 1996 by NASA which has successfully launched a 14-m diameter parabolic reflector using an inflatable membrane $[75,76]$.

A recent demonstration of a high gain S-band antenna (up to $21 \mathrm{dBi}$ ) was demonstrated [35]. More detailed assessments of the inflatable mechanisms have also been proposed by analyzing the diameter of the inflatable membrane using photogrammetric measurements [77-79]. Another inflatable membrane antenna depicted in Figure 10 was constructed in a concave shape using a reflective surface. The membrane inflation parameters were analyzed in terms of its reflector diameter, focal length, and inflation pressure [65].

6.4. Summary. The implementation of antennas, whether deployable or fixed on a CubeSat, must be performed with caution to ensure minimal effect of its structure on signal radiation. An improperly selected deployment mechanism may result in stowage space overuse in the already limited real estate on CubeSats. On the contrary, efficient space utilization for antenna or its stowage enables more physical space for payloads such as camera lens, sensors, and other applicationspecific components. Despite their limited sizes, CubeSats are available in multiples of $10 \mathrm{~cm}^{3}$, which can be cascaded to cater for larger capacities depending on the intended applications, at the expense of higher power utilization. As a result, deployment mechanisms for larger antennas with umbrella-like deployment and inflatable mechanisms could be realized. Besides that, antennas could also be considered

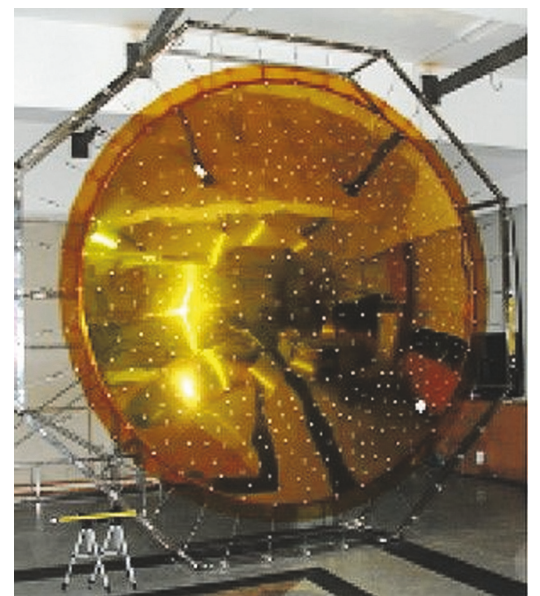

(a)

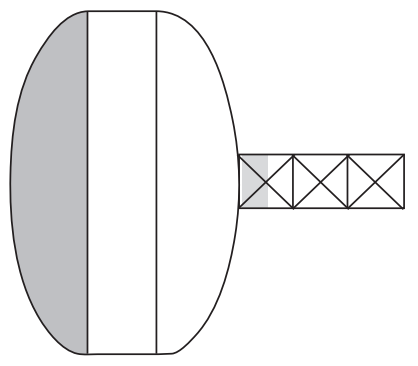

(b)

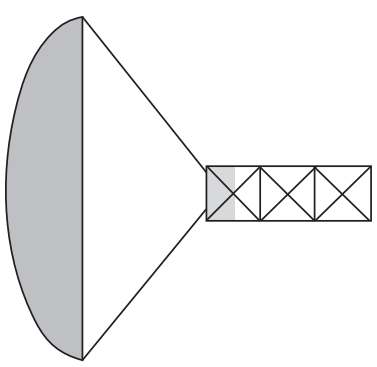

(c)
FIGURE 10: A model of the inflatable antenna proposed in $[35,65]$.

to be implemented along with deployable solar panels to cater to the increased power requirements due to the additional payloads and efficient space utilization at the same time. A summary of available CubeSat antennas and their stow-todeployment ratio is tabulated in Table 2.

\section{Conclusions and Future Perspectives}

This paper presents the review of antennas for picosatellites, including its applications and requirements and mechanism for deployment. Current applications for CubeSat include its use for observation, communication, education, and research, while its usage in other segments is still currently being studied. Its relatively short development time and cost efficiency are the attractive features which motivated its increasing popularity. Due to the nonstandard operating frequency, small available area, high gain, and circular polarization requirements, designing a CubeSat antenna is relatively challenging. Due to this, deployable antennas are becoming more of a necessity due to the electrical length at lower VHF/UHF bands and enhancing gain in the Sand V-bands. Due to this, deployable antenna must consider materials which are flexible and robust for operation in space. Issues in deployment such as the rigidity of the mechanical support structures, accuracy of the deployment, storage-todeployment size ratio, and maintenance of the inflation rate need to be addressed in future investigations. In recent years, 
frequency bands used for picosatellites are moving towards higher frequencies (Ka-band, V-band) for size reduction of radio frequency $(\mathrm{RF})$ payloads and to cater for higher speed data downlink. As a result, there is an intensive development of high such gain Ka-band antennas for picosatellites such as in the University of California, Los Angeles (UCLA) and the University of Kent, UK. Moreover, additional features for picosatellite antennas such as electronic beam steerable smart antennas will be employed for high-speed and power efficient data downlink and intersatellite wireless links. These compact-size low-power smart antennas will replace fixedbeam antennas currently in use and make future wireless systems more power efficient and flexible. Besides that, novel materials, components, and fabrication technologies will enable better performing picosatellites antennas at lower costs, such as $3 \mathrm{D}$ printing [80]. A number of established antenna models employing such $3 \mathrm{D}$ printing method are already proposed in [80-82]. Besides 3D printing technology, chip satellites and satellite-on-chip, and antennas on chip for such chip satellites are among other developments for future picosatellite technology, especially for CubeSat applications. Clearly, intersatellite links will be important for constellations of picosatellites, which requires the use of either multiple high gain antennas or antennas with beam switching and diversity techniques. More details of the state-of-the-art development for CubeSat antennas are also provided in [83].

\section{Conflicts of Interest}

The authors declare that there are no conflicts of interest regarding the publication of this paper.

\section{Acknowledgments}

This work has been partly supported by the Malaysian Ministry of Higher Education (MoHE) via the Prototype Development Research Grant Scheme (PRGS) (Grant no. 9013-00024) and the Thailand Research Fund under the TRF Senior Research Scholar Program (Contract no. RTA5780010).

\section{References}

[1] J. Puig-Suari, C. Turner, and W. Ahlgren, "Development of the standard CubeSat deployer and a CubeSat class picosatellite," in Proceedings of the IEEE Aerospace Conference, vol. 1, pp. 13471353, March 2001.

[2] J. Puig-Suari, C. Turner, and R. J. Twiggs, "CubeSat: the development and launch support infrastructure for eighteen different satellite customers on one launch," in Proceedings of the 15th Annual AIAA/Utah State University Conference on Small Satellites, pp. 1-5, 2001.

[3] https://en.wikipedia.org/wiki/Low_Earth_orbit.

[4] B. Klofas and K. Leveque, "A survey of CubeSat communication systems: 2009-2012," in Proceedings of the 10th Annual CubeSat Developers Workshop, pp. 1-41, Cal Poly State University, San Luis Obispo, Calif, USA, September 2012.

[5] Y. Rahmat-Samii and A. C. Densmore, "Technology trends and challenges of antennas for satellite communication systems,"
IEEE Transactions on Antennas and Propagation, vol. 63, no. 4, part 1, pp. 1191-1204, 2015.

[6] A. Toorian, K. Diaz, and S. Lee, "The CubeSat approach to space access," in Proceedings of the IEEE Aerospace Conference (AC '08), pp. 1-14, March 2008.

[7] B. Klofas, J. Anderson, and K. Leveque, "A survey of CubeSat communication system," in Proceedings of the CubeSat Developers Conference, 2008.

[8] RC America, Final Operational Report TIROS I Meteorological Satellite System, RC America, Princeton, NJ, USA, 1960.

[9] D. Selva and D. Krejci, "A survey and assessment of the capabilities of Cubesats for Earth observation," Acta Astronautica, vol. 74 , pp. 50-68, 2012.

[10] A. Chandra and S. Gosh, Remote Sensing and Geographical Information System, Alpha Science, Oxford, UK, 2006.

[11] J. Bouwmeester and J. Guo, "Survey of worldwide pico- and nanosatellite missions, distributions and subsystem technology," Acta Astronautica, vol. 67, no. 7-8, pp. 854-862, 2010.

[12] R. Sandau, "Status and trends of small satellite missions for Earth observation," Acta Astronautica, vol. 66, no. 1-2, pp. 1-12, 2010.

[13] K. Sarda, S. Eagleson, E. Caillibot et al., "Canadian advanced nanospace experiment 2: scientific and technological innovation on a three-kilogram satellite," Acta Astronautica, vol. 59, no. 1-5, pp. 236-245, 2006.

[14] W. J. Blackwell, L. J. Bickmeier, R. V. Leslie et al., "Hyperspectral microwave atmospheric sounding," IEEE Transactions on Geoscience and Remote Sensing, vol. 49, no. 1, part 1, pp. 128-142, 2011.

[15] M. Farison, K. Hicks, M. Schmidt, and S. Yang, Cloud CubeSat Thermoelectric Cooler Controller System, CiteSeerX, Baltimore, Md, USA, 2010.

[16] G. L. Stephens, D. G. Vane, S. Tanelli et al., "CloudSat mission: performance and early science after the first year of operation," Journal of Geophysical Research: Atmospheres, vol. 113, no. 8, Article ID D00A18, pp. 1-18, 2008.

[17] C. Kummerow, W. Barnes, T. Kozu, J. Shiue, and J. Simpson, "The Tropical Rainfall Measuring Mission (TRMM) sensor package," Journal of Atmospheric and Oceanic Technology, vol. 15, no. 3, pp. 809-817, 1998.

[18] S. Tanelli, S. L. Durden, E. Im et al., “CloudSat's cloud profiling radar after two years in orbit: performance, calibration, and processing," IEEE Transactions on Geoscience and Remote Sensing, vol. 46, no. 11, pp. 3560-3573, 2008.

[19] M. Kojima, T. Miura, K. Furukawa et al., "Dual-frequency precipitation radar (DPR) development on the global precipitation measurement (GPM) core observatory," in Earth Observing Missions and Sensors: Development, Implementation, and Characterization II, H. Shimoda, X. Xiong, C. Cao et al., Eds., vol. 8528 of International Society for Optical Engineering (SPIE Proceedings), 2012.

[20] E. Peral, S. Tanelli, Z. Haddad, O. Sy, G. Stephens, and E. Im, "Raincube: a proposed constellation of percipitation profiling radars in cubesat," in Proceedings of the IEEE International Symposium on Geoscience and Remote Sensing (IGARSS '15), vol. 1, pp. 1261-1264, 2015.

[21] P. C. Liewer, A. T. Klesh, and M. W. Lo, "A fractionated space weather base at L5 using CubeSats and solar sails," in Advances in Solar Sailing, Springer Praxis Books, pp. 269-288, Springer, Berlin, Germany, 2014. 
[22] J. Simonds, P. Mastro, D. O’Brien, and G. Sullivan, "Making SENSE: the SMC/XR space weather CubeSat demonstration," in Proceedings of the IEEE Aerospace Conference (AERO '11), pp. 17, IEEE, March 2011.

[23] E. Coleshill, J. Cain, F. Newland, and I. D'Souza, "NTS-A nanosatellite space trial," Acta Astronautica, vol. 66, no. 9-10, pp. 1475-1480, 2010.

[24] X. Yu and J. Zhou, "CubeSat: a candidate for the asteroid exploration in the future," in Proceedings of the 4th International Conference on Manipulation, Manufacturing and Measurement on the Nanoscale (3M-NANO '14), pp. 261-265, October 2014.

[25] A. Budianu, T. J. W. Castro, A. Meijerink, and M. J. Bentum, "Inter-satellite links for cubesats," in Proceedings of the IEEE Aerospace Conference (AERO '13), March 2013.

[26] A. Arvizu, J. Santos, E. Domínguez et al., "ATP subsystem for Optical Communications on a CubeSat," in Proceedings of the IEEE International Conference on Space Optical Systems and Applications (ICSOS '15), pp. 1-5, IEEE, October 2015.

[27] M. J. Bentum, C. J. M. Verhoeven, A. J. Boonstra, E. K. A. Gill, and A. J. van der Veen, "A novel astronomical application for formation flying small satellites," in Proceedings of the 60th International Astronautical Congress, pp. 1-8, Daejeon, Republic of Korea, October 2009.

[28] E. Gill, P. Sundramoorthy, J. Bouwmeester, and B. Sanders, "Formation flying to enhance the QB50 space network," in Proceedings of the Small Satellite Systems and Services Symposium, Funchal, Portugal, May 2012.

[29] R. T. Rajan, S. Engelen, M. Bentum, and C. J. M. Verhoeven, "Orbiting low frequency array for radio astronomy," in Proceedings of the IEEE Aerospace Conference (AERO '11), pp. 1-11, IEEE, March 2011.

[30] M. Werner, A. Jahn, E. Lutz, and A. Böttcher, "Analysis of system parameters for LEO/ICO-satellite communication networks," IEEE Journal on Selected Areas in Communications, vol. 13, no. 2, pp. 371-381, 1995.

[31] S. R. Pratt, R. A. Raines, C. E. Fossa, and M. A. Temple, "An operational and performance overview of the IRIDIUM low earth orbit satellite system," IEEE Communications Surveys \& Tutorials, vol. 2, no. 2, pp. 2-10, 1999.

[32] R. Lange and B. Smutny, "Optical inter-satellite links based on homodyne BPSK modulation: heritage, status, and outlook," in Proceedings of the Free-Space Laser Communication Technologies XVII, vol. 5712, pp. 1-274, April 2005.

[33] S. Gao, K. Clark, M. Unwin et al., "Antennas for modern small satellites," IEEE Antennas and Propagation Magazine, vol. 51, no. 4, 2009.

[34] A. R. Aslan, H. B. Yagci, M. E. Umit et al., "Development of a LEO communication CubeSat," in Proceedings of the 6th International Conference on Recent Advances in Space Technologies (RAST '13), pp. 637-641, June 2013.

[35] A. Babuscia, B. Corbin, M. Knapp, R. Jensen-clem, M. Van De Loo, and S. Seager, "Inflatable antenna for cubesats: motivation for development and antenna design," Elsevier, vol. 91, pp. 322332, 2013.

[36] A. Babuscia, M. Van de Loo, Q. J. Wei, S. Pan, S. Mohan, and S. Seager, "Inflatable antenna for CubeSat: fabrication, deployment and results of experimental tests," in Proceedings of the IEEE Aerospace Conference, IEEE, Big Sky, Mont, USA, March 2014.

[37] N. Chahat, J. Sauder, M. Thomson, R. Hodges, and Y. RahmatSamii, "CubeSat deployable Ka-band reflector antenna for Deep
Space missions," in Proceedings of the IEEE Antennas and Propagation Society International Symposium (APS '15), pp. 2185-2186, July 2015.

[38] C. Antenna, Y. He, S. Member, W. He, and H. Wong, "A wideband circularly polarized," IEEE Xplore: IEEE Antennas and Wireless Propagation Letters, vol. 13, pp. 67-70, 2014.

[39] Y. Luo, Q.-X. Chu, and L. Zhu, "A low-profile wide-beamwidth circularly-polarized antenna via two pairs of parallel dipoles in a square contour," IEEE Transactions on Antennas and Propagation, vol. 63, no. 3, pp. 931-936, 2015.

[40] Y. Luo, Q.-X. Chu, and L. Zhu, "A miniaturized wide-beamwidth circularly polarized planar antenna via two pairs of folded dipoles in a square contour," IEEE Transactions on Antennas and Propagation, vol. 63, no. 8, pp. 3753-3759, 2015.

[41] Nasimuddin, K. P. Esselle, and A. K. Verma, "Wideband highgain circularly polarized stacked microstrip antennas with an optimized C-type feed and a short horn," IEEE Transactions on Antennas and Propagation, vol. 56, no. 2, pp. 578-581, 2008.

[42] V. Rafii, J. Nourinia, J. Pourahmadazar, and F. Jalili, "Circularly polarized circular slot antenna array using sequentially rotated feed network," Journal of Communication Engineering, vol. 1, no. 1, pp. 37-45, 2012.

[43] S.-K. Lin and Y.-C. Lin, "A compact sequential-phase feed using uniform transmission lines for circularly polarized sequentialrotation arrays," IEEE Transactions on Antennas and Propagation, vol. 59, no. 7, pp. 2721-2724, 2011.

[44] C. Deng, Y. Li, Z. Zhang, and Z. Feng, "A wideband sequentialphase fed circularly polarized patch array," IEEE Transactions on Antennas and Propagation, vol. 62, no. 7, pp. 3890-3893, 2014.

[45] A. Nascetti, E. Pittella, P. Teofilatto, and S. Pisa, "High-gain S-band patch antenna system for earth-observation CubeSat satellites," IEEE Antennas and Wireless Propagation Letters, vol. 14, pp. 434-437, 2015.

[46] Nasimuddin, X. Qing, and Z. N. Chen, "Compact circularly polarized symmetric-slit microstrip antennas," IEEE Antennas and Propagation Magazine, vol. 53, no. 4, pp. 63-75, 2011.

[47] I. Park, S. X. Ta, J. J. Hin, and R. W. Ziolkowski, "Applications of circularly polarized crossed dipole antennas," in Proceedings of the International Workshop on Antenna Technology, pp. 3-5, Sydney, Australia, March 2014.

[48] S. X. Ta, I. Park, and R. W. Ziolkowski, "Circularly polarized crossed dipole on an HIS for 2.4/5.2/5.8-GHz WLAN applications," IEEE Xplore: IEEE Antennas and Wireless Propagation Letters, vol. 12, pp. 1464-1467, 2013.

[49] F. E. Shelton, "Cross-dipole antenna configurations," United States Patent, vol. 2, no. 12, 2012.

[50] H. H. Tran and I. Park, "Compact crossed dipole antenna for a broadband UHF-RFID tag," in Proceedings of the International Workshop on Antenna Technology (iWAT '15), pp. 379-380, Seoul, Republic of Korea, 2013.

[51] J. Costantine, Y. Tawk, A. Ernest, and C. G. Christodoulou, "Deployable antennas for CubeSat and space communications," in Proceedings of the 6th European Conference on Antennas and Propagation (EuCAP '12), pp. 837-840, Prague, Czech Republic, March 2012

[52] D. Misman, I. A. Salamat, M. F. Abdul Kadir et al., "The study of meander line for microstrip and planar design," in Proceedings of the 8th International Conference on Intelligent Transport System Telecommunications (ITST '08), pp. 24-28, October 2008. 
[53] D. Ochoa, K. Hummer, and M. Ciffone, "Deployable helical antenna for nano-satellites," in Proceedings of the 28th Annual AIAA/USU Conference on Small Satellites, pp. 1-7, Logan, Utah, USA, August 2014.

[54] C. J. Vourch and T. D. Drysdale, "V-Band 'Bull's Eye' antenna for CubeSat applications," IEEE Antennas and Wireless Propagation Letters, vol. 13, pp. 1092-1095, 2014.

[55] H.-T. Liu, S. Gao, and T.-H. Loh, "Electrically small and low cost smart antenna for wireless communication," IEEE Transactions on Antennas and Propagation, vol. 60, no. 3, pp. 1540-1549, 2012.

[56] M. T. Islam, M. Cho, M. Samsuzzaman, and S. Kibria, "Compact antenna for small satellite applications [Antenna Applications Corner]," IEEE Antennas and Propagation Magazine, vol. 57, no. 2, pp. 30-36, 2015.

[57] C. J. Vourch and T. D. Drysdale, "Inter-CubeSat communication with V-band 'Bull's eye' antenna," in Proceedings of the 8th European Conference on Antennas and Propagation (EuCAP '14), pp. 3545-3549, April 2014.

[58] R. E. Freeland, G. D. Bilyeu, and M. M. Mikulas, Inflatable Deployable Space Structures Technology Summary, International Aeronautical Federation, 1998.

[59] H.-J. Wang, F. Bin, Y. Min et al., "Inflatable antenna for space-borne microwave remote sensing," IEEE Antennas and Propagation Magazine, vol. 54, no. 5, pp. 58-70, 2012.

[60] W. You-Wei and G. Fu-Ling, "Design and fabrication of a folding-and-rolling reflectarray antenna," in Proceedings of the 8th International Symposium on Antennas, Propagation and EM Theory (ISAPE '08), pp. 54-57, November 2008.

[61] A. Chauraya, W. G. Whittow, Y. C. Vardaxoglou et al., "Inkjet printed dipole antennas on textiles for wearable communications," IET Microwaves, Antennas and Propagation, vol. 7, no. 9, pp. 760-767, 2013.

[62] H. R. Khaleel, H. M. Al-Rizzo, D. G. Rucker, and S. Mohan, "A compact polyimide-based UWB antenna for flexible electronics," IEEE Antennas and Wireless Propagation Letters, vol. 11, pp. 564-567, 2012.

[63] S. Ahmed, F. A. Tahir, A. Shamim, and H. M. Cheema, "A compact kapton-based inkjet-printed multiband antenna for flexible wireless devices," IEEE Antennas and Wireless Propagation Letters, vol. 14, pp. 1802-1805, 2015.

[64] H. R. Khaleel, H. M. Al-Rizzo, and D. G. Rucker, "Compact polyimide-based antennas for flexible displays," IEEE/OSA Journal of Display Technology, vol. 8, no. 2, pp. 91-96, 2012.

[65] Y. Xu and F.-L. Guan, "Structure design and mechanical measurement of inflatable antenna," Acta Astronautica, vol. 76, pp. 13-25, 2012.

[66] S. Cakaj, B. Kamo, A. Lala, and A. Rakipi, "The coverage analysis for low earth orbiting satellites at low elevation," International Journal of Advanced Computer Science \& Applications, vol. 5, no. 6, pp. 6-10, 2014.

[67] T. Inamori, K. Otsuki, Y. Sugawara, P. Saisutjarit, and S. Nakasuka, "Three-axis attitude control by two-step rotations using only magnetic torquers in a low Earth orbit near the magnetic equator," Acta Astronautica, vol. 128, pp. 696-706, 2016.

[68] T. F. C. Leao, V. Mooney-Chopin, C. W. Trueman, and S. Gleason, "Design and implementation of a diplexer and a dualband VHF/UHF antenna for nanosatellites," IEEE Antennas and Wireless Propagation Letters, vol. 12, pp. 1098-1101, 2013.

[69] Y. Tsuda, N. Sako, T. Eishima et al., "University of Tokyo's CubeSat project: its educational and technological significance," in Proceedings of the 15th Annual AIAA/USU Conference on Small Satellites (SSC '01), pp. 1-8, 2001.

[70] J. Costantine, Y. Tawk, C. G. Christodoulou, J. Banik, and S. Lane, "Cubesat deployable antenna using bistable composite tape-springs," IEEE Antennas and Wireless Propagation Letters, vol. 11, pp. 285-288, 2012.

[71] N. Chahat, R. E. Hodges, J. Sauder, M. Thomson, E. Peral, and Y. Rahmat-Samii, "CubeSat deployable Ka-band mesh reflector antenna development for earth science missions," IEEE Transactions on Antennas and Propagation, vol. 64, no. 6, pp. 2083-2093, 2016.

[72] R. E. Hodges, M. J. Radway, A. Toorian, D. J. Hoppe, B. Shah, and A. E. Kalman, "ISARA-integrated solar array and reflectarray CubeSat deployable Ka-band antenna," in Proceedings of the IEEE Antennas and Propagation Society International Symposium (APS '15), pp. 2141-2142, July 2015.

[73] R. E. Hodges, D. J. Hoppe, M. J. Radway, and N. E. Chahat, "Novel deployable reflectarray antennas for CubeSat communications," in Proceedings of the IEEE MTT-S International Microwave Symposium (IMS '15), pp. 1-4, IEEE, May 2015.

[74] H. Heidt, P. J. Puig-Suari, P. A. S. Moore, P. S. Nakasuka, and P. R. J. Twiggs, "CubeSat: a new generation of picosatellite for education and industry low-cost space experimentation," in Proceedings of the 14th Annual AIAA/USU Conference on Small Satellites, pp. 1-19, 2013.

[75] R. E. Freeland, G. D. Bilyeu, G. R. Veal, M. D. Steiner, and D. E. Carson, "Large inflatable deployable antenna flight experiment results," Acta Astronautica, vol. 41, no. 4-10, pp. 267-277, 1997.

[76] R. E. Freeland, G. D. Bilyeu, and G. R. Veal, "Development of flight hardware for a large, inflatable-deployable antenna experiment," Acta Astronautica, vol. 38, no. 4-8, pp. 251-260, 1996.

[77] R. S. Pappa, L. R. Giersch, and J. M. Quagliaroli, Photogrammetry of a $5 \mathrm{~m}$ Inflatable Space Antenna with Consumer Digital Cameras, NASA, 2000.

[78] E. Flint, G. Bales, and R. Glaese, "Experimentally characterizing the dynamics of $0.5 \mathrm{~m}+$ diameter doubly curved shells made from thin films," in Proceedings of the 44th AIAA/ASME/ASCE/AHS/ASC Structures, Structural Dynamics, and Materials Conference, AIAA 2003-1831, pp. 1-11, 2003.

[79] R. S. Pappa, J. O. Lassiter, and B. P. Ross, "Structursl dynamics experimental activities in ultra-lightweight and inflatable space structures," in Proceedings of the 42nd AIAA/ASME/ASCE/AHS/ASC Structures, Structural Dynamics and Materials Conference, vol. 1263, pp. 1-18, Seattle, Wash, USA, April 2001.

[80] J. A. Vilán Vilán, F. Aguado Agelet, M. López Estévez, and A. González Muiño, "Flight results: reliability and lifetime of the polymeric 3D-printed antenna deployment mechanism installed on Xatcobeo \& Humsat-D," Acta Astronautica, vol. 107, pp. 290-300, 2015.

[81] M. F. Farooqui and A. Shamim, "3-D inkjet-printed helical antenna with integrated lens," IEEE Antennas and Wireless Propagation Letters, vol. 16, pp. 800-803, 2016.

[82] B. Majumdar, D. Baer, S. Chakraborty, K. Esselle, and M. Heimlich, "A 3D printed dual-ridged horn antenna," in Proceedings of the International Conference on Electromagnetics in Advanced Applications (ICEAA '16), pp. 836-839, Cairns, Australia, September 2016. 
[83] Y. Rahmat-Samii, V. Manohar, and J. M. Kovitz, "For satellites, think small, dream big: a review of recent antenna developments for CubeSats," IEEE Antennas and Propagation Magazine, vol. 59, no. 2, pp. 22-30, 2017.

[84] S. K. Podilchak, M. Caillet, D. Lee et al., "Compact antenna for microsatellite using folded shorted patches and an integrated feeding network," in Proceedings of the 6th European Conference on Antennas and Propagation (EuCAP '12), pp. 1819-1823, March 2012. 


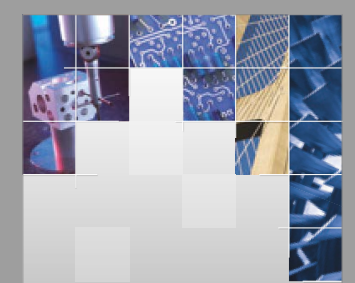

\section{Enfincering}
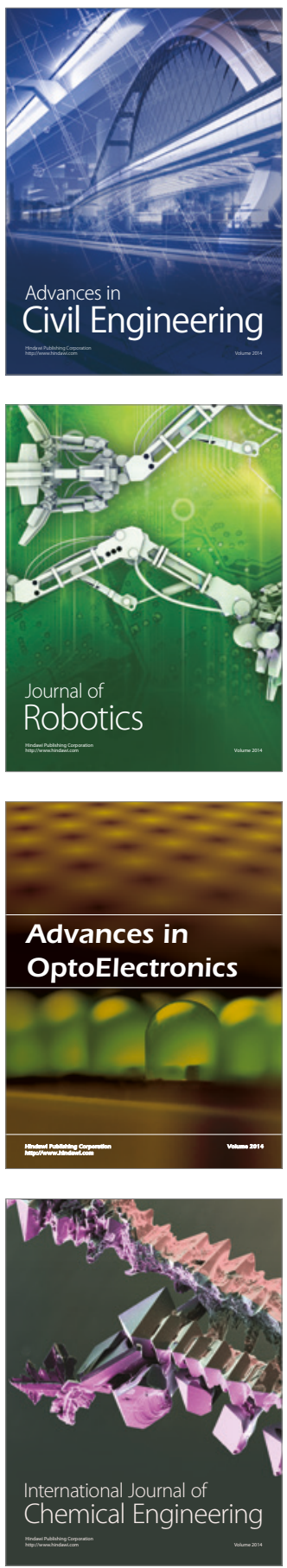

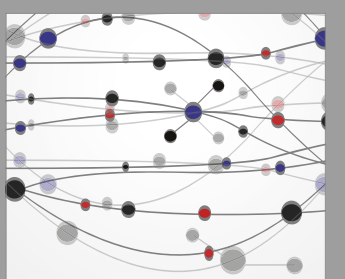

The Scientific World Journal

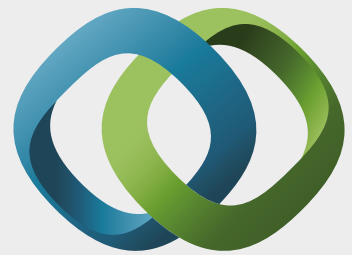

\section{Hindawi}

Submit your manuscripts at

https://www.hindawi.com
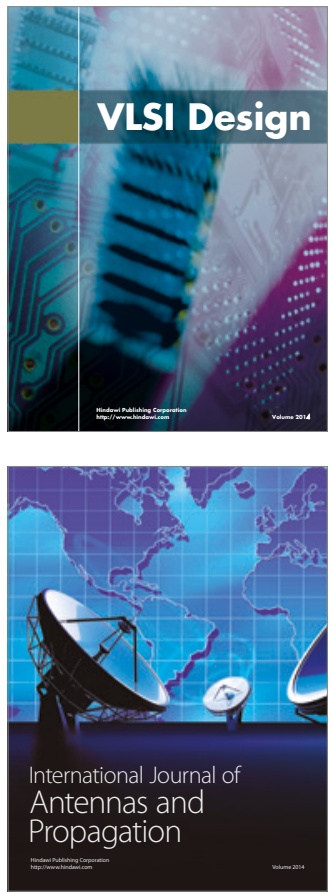

\section{Rotating}

Machinery
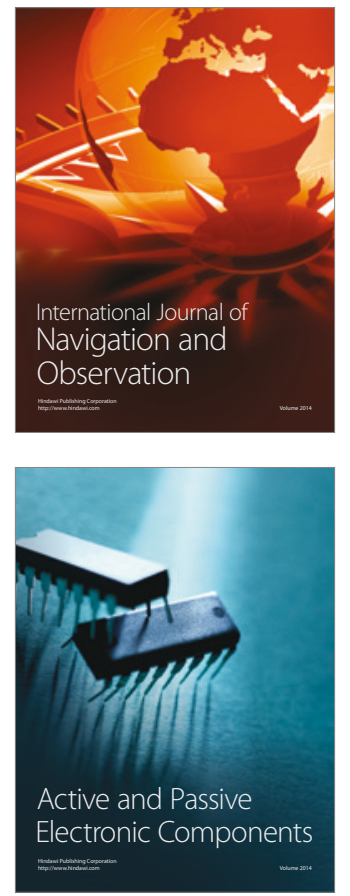
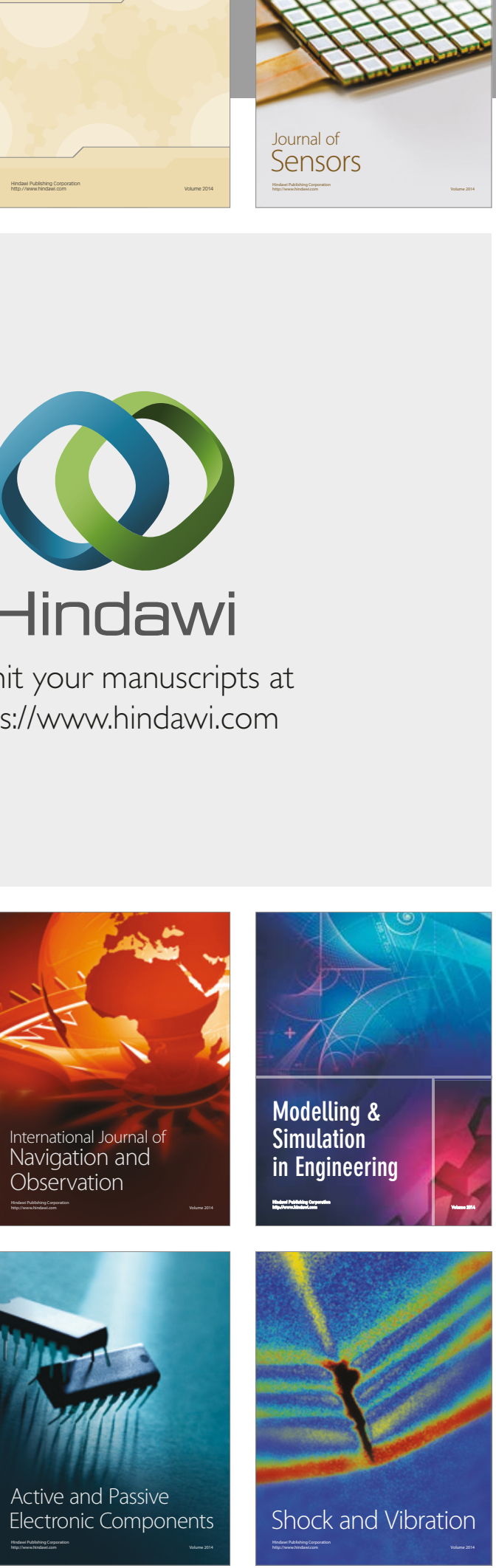
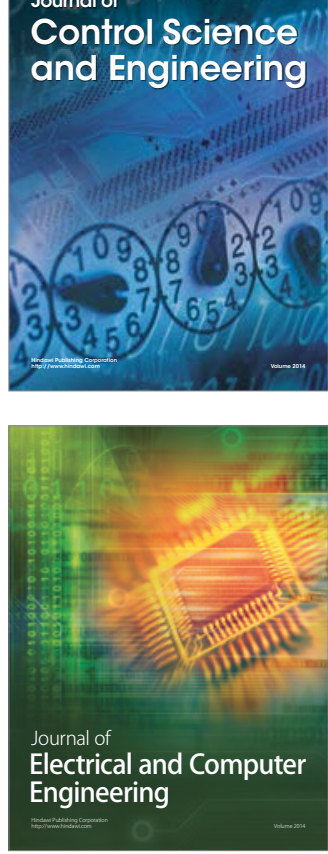

Distributed

Journal of

Control Science

and Engineering
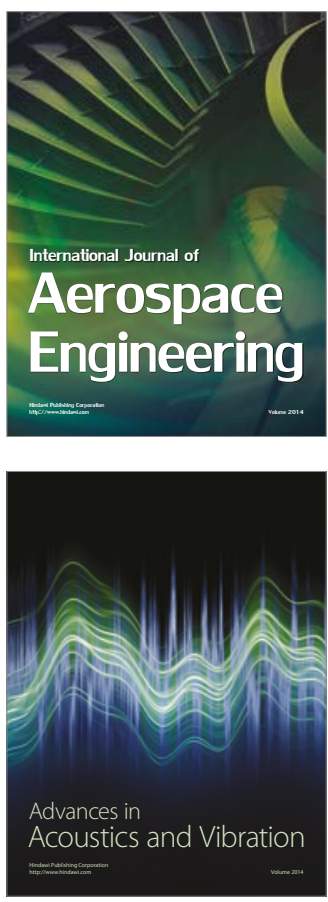

Sensor Networks 